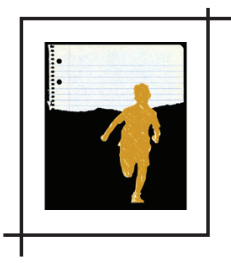

\title{
COMUNICAÇÃO DO BINÔMIO INDISSOCIÁVEL NA ESCOLA: EDUCAÇÃO E SAÚDE
}

\author{
Neudson Johnson Martinho* \\ Celso Luiz Prudente** \\ Dacirlene Célia Silva***
}

Resumo: Este artigo objetiva discutir o binômio educação e saúde no ambiente escolar. Aponta problemáticas do final do século XVIII levantadas pelo alemão Johann Peter Frank (1745-1821), o qual publicou em 1779 na Alemanha, um guia intitulado System Einer Vollstãndigen Medicinischen (1976). Saúde escolar é pensada em programas voltados para sua implementação. Lescura e Mamede (1990) ressaltam que a educação em saúde nas escolas é uma prática educativa. No Brasil, a saúde imbricada na educação e vice-versa possibilitou a existência de problematizações sobre a infância e adolescência, as etapas do ciclo vital e a saúde em Programa Saúde na Escola - PSE na ambiência escolar, para a concretização de termos famílias saudáveis e um mundo com cultura de paz, saúde mental e exercício da cidadania desde a infância. Com o intuito de dinamizar as relações dos atores da saúde pública em um processo de integração educacional, foram analisados a ação e projetos das Equipes de Saúde da Familia, a necessidade de inserção técnica no Programa Saúde na Escola - Grupo de Pesquisas Multiprofissionais em Educação e Tecnologias em Saúde (Pemeduts) da Faculdade de Medicina da Universidade Federal de Mato Grosso (UFMT), campus Cuiabá - Projeto de Extensão com interface na pesquisa: "Diálogo e práxis: inovando práticas pedagógicas em educação em saúde nas escolas" durante os anos 2016, 2017 e 2018, em três escolas municipais de Cuiabá: Emeb Maria Lucila da Silva Barros, Emeb Prof. Zeferino Leite de Oliveira e a Emeb Maximiano Arcanjo.

Palavras-chave: Educação. Saúde. Comunicação. Ambiente Escolar. Projeto.

\footnotetext{
* Doutor em Educação pela Universidade Federal de Mato Grosso (UFMT). Professor adjunto da Faculdade de Medicina da UFMT. Líder do Grupo de Pesquisas Multiprofissionais em Educação e Tecnologias em Saúde da UFMT e coordenador do Comitê de Ética em Pesquisa em Seres Humanos/Saúde/UFMT. E-mail: neudsonjm@hotmail.com

** Pós-doutor em Linguística pela Universidade Estadual de Campinas (Unicamp) e doutor em Cultura pela Universidade de São Paulo (USP). Professor associado da Universidade Federal de Mato Grosso (UFMT). Pesquisador do Centro de Estudos Latino-Americanos sobre Cultura e Comunicação (Celacc) da USP. Antropólogo, cineasta e curador da Mostra Internacional do Cinema Negro.E-mail: clsprudente@gmail.com

*** Pós-graduada em Arquivistica, em Negócios Imobiliários e em Docência no Ensino Superior. Bibliotecária e teóloga. E-mail: darce.celia@gmail.com br
} 


\section{INTRODUÇÃO}

Desde o final do século XVIII, o binômio educação e saúde vem sendo apontado como importante e necessário no ambiente escolar pelo alemão Johann Peter Frank (1745-1821), o qual publicou em 1779, na Alemanha, um guia intitulado System Einer Vollstãndigen Medicinischen, sendo a versão inglesa A system of complete medical police (1976), que passou a ser conhecido como Sistema Frank. Nesse guia, o autor ressaltava a importância da saúde escolar em todo o mundo e dava subsídios para a elaboração de programas voltados para a implementação desta, visando à educação e saúde para as crianças (FIGUEIRED0; MACHADO; ABREU, 2010).

Lescura e Mamede (1990) ressaltam que a educação em saúde nas escolas é uma prática educativa que contribui para o desenvolvimento de saberes e valores que estimulam padrões de vida saudável no indivíduo e na sociedade.

No Brasil, em 2007, o presidente da República na época, Luiz Inácio Lula da Silva, assinou o Decreto n. 6.286, de 5 de dezembro de 2007, que dispõe no item I do artigo 20: "promover a saúde e a cultura da paz, reforçando a prevenção de agravos à saúde, bem como fortalecer a relação entre as redes públicas de saúde e de educação". Esse decreto instituiu o Programa Saúde na Escola (PSE), entendendo que a promoção da saúde conjugada com a preocupação da educação indica a possibilidade da cultura de paz (BRASIL, 2007).

Dessa forma, "contribuir para a constituição de condições para a formação integral de educandos", com a observância em proveito de "fortalecer o enfrentamento das vulnerabilidades, no campo da saúde, que possam comprometer o pleno desenvolvimento escolar", como visto, respectivamente nos itens III e $\mathrm{V}$, do artigo $2^{\circ}$ desse mesmo decreto.

Com o propósito de estabelecer "recursos financeiros pela adesão ao PSE para Municípios com equipes de Saúde da Família, priorizados a partir do Índice de Desenvolvimento da Educação Básica (IDEB), que aderirem ao Programa Saúde na Escola (PSE)", o governo federal, por meio do Ministério da Saúde (MS), edita a Portaria n. 1.861, de 4 de setembro de 2008. De acordo com essa portaria, a Secretaria Municipal de Saúde (SMS) tem a compulsoriedade de preencher, no Sistema de Cadastro Nacional de Estabelecimentos de Saúde (SCNES), o campo específico de identificação das equipes de Saúde da Família (eSF) que atuarão no PSE. Esse comportamento parece reforçar o comprometimento da política de Estado em rever a lacuna que ainda se percebia no esforço de ação integrada da educação e da saúde, visando à modernidade da cultura de paz.

Sabe-se que a saúde e a educação implicam problemas que demandam a teleologia do serviço público e o dilema do consumo. Lembrando que os setores do consumo têm suas necessidades fora da esfera do Estado, exceto no que diz respeito ao ensino superior, já que, nesse caso específico, a demanda estatal é objeto exclusivo dos setores que estão fora do seu alcance. Embora essa contradição evidente seja pouco percebida, a sua expressão caracteriza 
a assimetria social estabelecida em relações raciais, em um processo de cores das relações socioeconômicas.

O serviço público de saúde tem amplas faixas de consumo de pessoas escurecidas e empobrecidas, e quase não se percebem aí os segmentos claros e enriquecidos. Contudo, essa contradição se repete nas escolaridades dos ensinos fundamental e médio que têm sua clientela escurecida, em que o serviço fica aquém do seu desígnio. Com a mesma lógica, no ensino universitário a faixa de consumo é diminuta e clara, demandando um atendimento de qualidade, e raramente se veem aí as amplas massas escuras e miscigênicas. Isso significa que as relações públicas de saúde e de escolaridade implicam um consumo suficiente da cor branca do eurodescendente, exclusivamente na escolaridade universitária para o atendimento da imagem do euro-hétero-macho-autoritário (PRUDENTE, 2019a).

Isso é diferente de uma relação insuficiente de consumo de cor branca do ibérico-descendente pobre, do amarelo asiodescendente, do preto afrodescendente e do vermelho ameríndio-descendente, que formam uma assimetria social do ibero-ásio-afro-ameríndio, que se constitui como minoria vulnerável diante do poder econômico da euro-heteronormatividade percebido nos convênios médicos e nos ensinos fundamental e médio privados (PRUDENTE, 2019b, 2020).

Com o intuito de dinamizar as relações dos atores da saúde pública em um processo de integração educacional, foi percebida uma ação que instituiu aos profissionais das eSF a necessidade de inserção técnica no PSE, objetivando mais atenção a esses setores para uma atuação eficaz, diante desses problemas econômicos implicados nas relações sociorraciais.

Percebemos a dificuldade desse empreendimento de integração de saúde e educação na percepção das constantes instituições e revogações das medidas afins. Como se observa a nova Portaria Interministerial n. 1.413/2013, que "Redefine as regras e critérios para adesão ao Programa Saúde na Escola (PSE) por Estados, Distrito Federal e Municípios e dispõe sobre o respectivo incentivo financeiro para custeio de ações", de tal sorte que se vê nas determinações a estratégia de integrar no processo atores afins, mas antes dispersos como se vê no parágrafo IV do artigo $4^{\circ}$ da referida portaria: "IV - ao aderir ao PSE, o gestor de saúde do Município ou do Distrito Federal poderá aderir, concomitantemente, ao Projeto Olhar Brasil, cujos procedimentos encontram-se previstos em ato específico do Ministério da Saúde" (BRASIL, 2013).

Essa ação aperfeiçoa as relações de atendimento no esforço da concorrência pela eficácia em meio a tantos problemas sociais. Essa portaria que "redefine as regras e critérios para adesão ao Programa Saúde na Escola (PSE)" parece testemunhar o discernimento de que, para além de dificuldades de relações socioeconômicas, há também as celeumas das dispersões de recursos humanos que prejudicam as gestões das políticas públicas.

A assimetria social tem reflexo racial que se estabelece também como diferença de regionalidade vista nos municípios que é o ente de relações factuais, na medida em que é o lugar 
das pessoas para além do Estado e do campo federal, que são abstrações dadas no campo político, como já observava o professor e jurista André Franco Montoro (apud BARBOSA, 2006): "Ninguém vive na União ou no estado. As pessoas vivem no município".

A ação integradora de saúde e educação quer alcançar a vulnerabilidade que se localiza no município:

Art. $8^{\circ}$ Compete ao GTI Municipal do PSE (GTI-M):

I - apoiar a implementação dos princípios e diretrizes do PSE no planejamento, monitoramento, execução, avaliação e gestão dos recursos financeiros;

II - articular a inclusão dos temas relacionados às ações do PSE nos projetos políticos pedagógicos das escolas;

III - definir as escolas públicas federais, estaduais (em articulação com o Estado) e municipais a serem atendidas no âmbito do PSE, considerando-se as áreas de vulnerabilidade social, os territórios de abrangência das Equipes de Atenção Básica e os critérios indicados pelo Governo Federal (BRASIL, 2013).

Nessa linha de abordagem, observamos que, em Cuiabá-MT, na região amazônica, as faixas sociais são amplas e mostram inequívoca configuração miscigênica que acompanha a assimetria social refletida na educação e na saúde. Esse fenômeno de vulnerabilidade socioeconômica de expressão racial ocorre a despeito do inegável poder econômico do agronegócio de expressão eurocaucasiana (PRUDENTE, 2019b). De tal sorte que o PSE foi implantado pela prefeitura em 2008, por meio do Decreto Municipal n. 4.684, visando contribuir para a formação integral dos estudantes da rede municipal de educação e promover a saúde deles com base nos princípios do Sistema Único de Saúde (SUS). Essa formação é modificada à medida que novas determinações são emitidas pelo MS.

Art. 3॰ 0 Programa Escola com Saúde tem como diretrizes:

Reforçar a prevenção de agravos à saúde;

Fortalecer a relação institucional entre as redes públicas municipais de saúde e de educação;

Promover a cultura institucional da prevenção no âmbito escolar;

Enfrentar as vulnerabilidades, no campo da saúde, que possam comprometer o pleno desenvolvimento escolar;

Promover a comunicação entre escolas e unidades de saúde, assegurando a troca de informações sobre as condições de saúde dos estudantes de 0 a 14 anos;

Contribuir com informações básicas de saúde pública, repassadas aos trabalhadores da educação (CUIABÁ, 2008). 
A Secretaria de Estado de Saúde (SES) de Mato Grosso divulgou que, para o PSE no ciclo 2019/2020, "houve a adesão de 139 cidades, alcançando 98\% dos municípios mato-grossenses" (VELASCO, 2019), um recorde histórico para o estado. De acordo com Milton Fleury (apud VELASCO, 2019), um dos representantes do PSE: "Os municípios mato-grossenses demonstraram, mais uma vez, grande compromisso e empenho em oferecer qualidade de vida e saúde aos estudantes mato-grossenses".

0 alunado das escolas e creches da municipalidade cuiabana será provido do atendimento público nas diversas áreas da saúde preventiva, e essa profilaxia será feita por equipes de profissionais da Saúde da Família, buscando acuidade mais ampla, que entende o binômio indissolúvel da saúde e educação na escolaridade municipal (VELASCO, 2019), fenômeno que tem sido também objeto de preocupação acadêmica, como observam Silva et al. (2010):

\footnotetext{
A partir de então, inicia-se um periodo em que as práticas educativas, da forma como estavam estruturadas, são submetidas a questionamentos e reflexões, sob influência das transformações que ocorriam no campo da Pedagogia. Neste contexto, novos conceitos e práticas passam a ser defendidos no âmbito da Educação em Saúde, principalmente entre estudiosos oriundos da universidade.
}

Nessa linha de preocupação, Velasco (2019) demonstra que, com o resultado alcançado, 1.553 escolas serão contempladas, o que representa 461.070 alunos de escolas públicas e mais 46.234 alunos de 401 creches públicas beneficiadas.

De acordo com Melo (1987, p. 28), existe uma preocupação em relação à "articulação entre a saúde e a educação, integradas nas propostas das políticas oficiais". Nessa perspectiva, vimos, com efeito, que nosso artigo tem relação dialógica com essa preocupação, quando chama a atenção para o fato de que, desde o século XVIII, a educação e a saúde foram identificadas como um binômio imbricado existencialmente sob o ponto de vista humano.

Melo (1987) afirma que a educação e a saúde sempre estiveram articuladas como práticas sociais, cuja tendência nas últimas décadas é legitimá-las no Brasil como parte do trabalho do médico, dos demais profissionais da saúde e do educador.

Delors (1999) corrobora a afirmação de Melo (1987) afirmando que esse processo educativo com vista à saúde deve estar presente na educação das crianças, para se formar uma cultura pedagógica com base na profilaxia da saúde. Partimos do princípio de que a saúde e a educação são inseparáveis e interdependentes, considerando que não se consegue ter educação sem ter saúde, ao mesmo tempo que a saúde só é alcançável quando se tem uma boa educação.

Portanto, trata-se de uma compreensão social que sugere um alcance popular na medida em que essa indissociabilidade do binômio saúde e educação está implícita e explícita no cotidiano da necessidade dos amplos segmentos do consumo público em que se percebe a 
vulnerabilidade. Esse fenômeno compromete as relações institucionais, sugerindo possivelmente fragilidade na democracia. Por um processo perceptivo, temos insistido nesta reflexão, da possibilidade de relações institucionais com base em seleção censitária, que indica a manutenção de um poder de pequenos grupos euro-ocidentais de privilégio que se dão em detrimento de amplos segmentos miscigênicos percebidos na possivel imagem de horizontalidade do ibero-ásio-afro-ameríndio (PRUDENTE, 2019a). Isso nos parece, "a nosso quase cego ver", que essa força miscigênica sofre uma desarticulação da hegemonia imagética do euro-hétero-macho-autoritário, que temos insistido ser determinado por uma euro-heteronormatividade que parece presente na estrutura das relações institucionais, sugerindo um estado de tendência racial classista (PRUDENTE, 2018).

0 binômio indissociável em voga sugere ser um pressuposto de direitos adquiridos, por serem considerados direitos do povo e dever do Estado, tendo assim um caráter político-social polêmico (DELORS, 1999).

Objetivamos com este artigo socializar uma ação de educação em saúde desenvolvida em escolas municipais de Cuiabá-MT, a qual legitima que a escola pode ser um espaço privilegiado para promoção da saúde com as crianças, os professores e os gestores escolares.

Abordar essa temática educação-saúde com criança se reveste de relevância social e acadêmica por possibilitar reflexões propositivas para as áreas da educação e da saúde quanto à prática desse binômio, necessário à saúde não só da criança, mas também da sociedade como um todo, demonstrando que as atividades dos profissionais da saúde podem transcender os muros dos hospitais, dos postos de saúde e das prescrições medicamentosas. Educar na ambiência escolar quanto aos cuidados inerentes à saúde pode ser uma ação transformadora na vida dos escolares, de modo a possibilitar que eles se tornem sujeitos ativos na arte de se autocuidar e cuidar da saúde no microespaço social (família) e no meso (comunidade).

A escola é um espaço de múltiplas aprendizagens inerentes ao viver humano, as quais devem ser articuladas e contextualizadas na realidade de vida vivida pelos aprendizandos. A educação e a saúde são fenômenos imbricados, devendo fazer parte do processo educativo na escola (MARTINHO, 2018).

\section{METODOLOGIA}

0 Grupo de Pesquisas Multiprofissionais em Educação e Tecnologias em Saúde (Pemeduts) da Faculdade de Medicina da Universidade Federal de Mato Grosso (UFMT), campus Cuiabá, desenvolveu o projeto de extensão com interface na pesquisa "Diálogo e práxis: inovando práticas pedagógicas em educação em saúde nas escolas" durante os anos 2016, 2017 e 2018, em três escolas municipais de Cuiabá: Escola Municipal de Educação Básica (Emeb) 
Maria Lucila da Silva Barros, Emeb Prof. Zeferino Leite de Oliveira e Emeb Maximiano Arcanjo. Esse projeto só iniciou suas atividades após ser submetido ao Comitê de Ética em Pesquisa com Seres Humanos do Hospital Júlio Muller/UFMT e ser aprovado, recebendo o Parecer de Aprovação n. 1.637.600/2016.

0 projeto supracitado teve com objetivo geral realizar atividades de educação em saúde nas escolas abordando as diversas dimensões da existência e sobrevivência humana em um processo relacional. Por sinal, essas relações se estabelecem concomitantemente, na medida em que segmentos vulneráveis e marginalizados vivem a negação da relação de poder, mas não deixam de rearticular nesse processo a sua humanidade, por um processo abissal de relações rizomáticas (DELEUZE; GUATTARI, 2011; RIBEIRO, 2019).

Essa ação investigativa foi feita com gestores, professores e funcionários das escolas lócus da pesquisa, visando contribuir com esses atores sociais em implementações de metodologias ativas na arte de educar em saúde no contexto escolar, cuja execução ocorreu em dois momentos: o primeiro com os docentes e gestores escolares, em que abordamos aspectos referentes às metodologias de educação em saúde, e o segundo com os escolares (crianças e adolescentes), em que buscamos identificar, a partir das percepções deles, quais as melhores estratégias para que se apropriassem de saberes e fazeres inerentes à promoção da saúde na ambiência da escolaridade, como políticas públicas da municipalidade:

Prefeitura de Cuiabá-MT através do Decreto municipal n 4.684, implantou o Programa Saúde na Escola (PES) em 2008, ressignificando-o à realidade local, visando contribuir para a formação integral dos estudantes da rede municipal de educação e promover a saúde dos mesmos, com base nos princípios do SUS (MARTINHO, 2018).

Desenvolveram-se várias atividades de demandas metodológicas, as quais se caracterizaram por: roda de conversa, círculo de cultura, modelo de crença em saúde e mapeamento semântico. Todas foram realizadas com base no método pedagógico de Paulo Freire (1967, 1974, 1996), tendo temas geradores e implementados com dinâmicas contextuais, estimulando a participação ativa de todos os envolvidos, demandadas por uma dialogicidade no processo de ensino-aprendizagem a partir dos espaços de fala e escuta ativa.

Os temas geradores foram sugeridos pelos professores e gestores escolares, sendo: drogadicção, sexualidade humana, qualidade de vida e teorias da abordagem comportamental. No tema que abordou as teorias da abordagem comportamental, vários subtemas foram abordados, como dislexia, dislalia, autismo e disfemia.

Em sintese, o referido projeto se desenvolveu com as seguintes etapas de execução: 1. seleção em parceria com a SMS e Secretaria de Educação (Seduc) de Cuiabá quanto às escolas que seriam contempladas com o projeto de extensão/pesquisa; 2. realização de oficinas pedagógicas com alunos bolsistas do projeto e profissionais da equipe Escola com Saúde de 
Cuiabá-MT; 3. visitas às escolas para contrato verbal com os gestores e docentes; 4. realização de oficina pedagógica com os docentes e gestores das escolas selecionadas; 5 . realização de ações de educação em saúde com as crianças e os adolescentes das escolas; 6. elaboração de proposições de abordagens pedagógicas em saúde com crianças/adolescentes a partir das vivências nas oficinas realizadas; 7. avaliação e elaboração do relatório final do projeto; 8. elaboração de trabalhos a serem apresentados em eventos científicos locais, regionais e nacionais; 9 . elaboração de artigo com resultados do projeto a ser publicado em periódico de extensão da UFMT e em outros periódicos das áreas de educação e saúde; 10. elaboração de uma cartilha educativa contendo as principais dinâmicas realizadas para educação em saúde na escola.

Esses procedimentos nos possibilitaram apreender, por meio das narrativas dos participantes das rodas de conversa, fenômenos inerentes às lacunas na formação docente quanto à abordagem sobre educação em saúde na escola, assim como a necessidade de se criar uma ferramenta que viabilizasse esse processo educativo, considerando a percepção dos principais atores sociais dessa ação: crianças e adolescentes.

\section{RESULTADOS}

Visando à melhor compreensão e visualização comunicativa quanto ao desenvolvimento do projeto em sua totalidade, utilizamos de forma adaptada a "roda representativa" proposta pela Associação Brasileira de Educação Médica - Abem (2009), na qual descrevemos os processos operacionais, temas e materiais usados.

A roda é composta por cinco eixos e 16 vetores. Cada vetor é indicado em três momentos: avaliação interna, construção dos indicadores e avaliação externa, as quais são representadas nos círculos interno, intermédio e externo.

0 processo comunicacional caracterizado nas falas dos professores e das gestoras escolares foi sistematizado e consolidado, e, assim, procedemos à análise, que mostrou consenso entre os participantes no tocante ao impacto positivo das rodas de conversas como dinâmica que muito contribuiu para novas aprendizagens, de modo específico quanto a saber realizar educação em saúde na ambiência escolar.

Observamos, nas análises dos procedimentos, que os professores destacaram como aprendizagem que os marcou no projeto o fato de terem compreendido que a dislexia, a dislalia e a disfemia não necessariamente são de origem neurológica, psicológica ou psiquiátrica, podendo ter origem nutricional ou bioquímica, como um desequilibrio hidroeletrolítico. Referiram existirem na escola alunos com tais disfunções e sempre consideraram apenas como de causa neurológica. 
Figura 1 Roda representativa

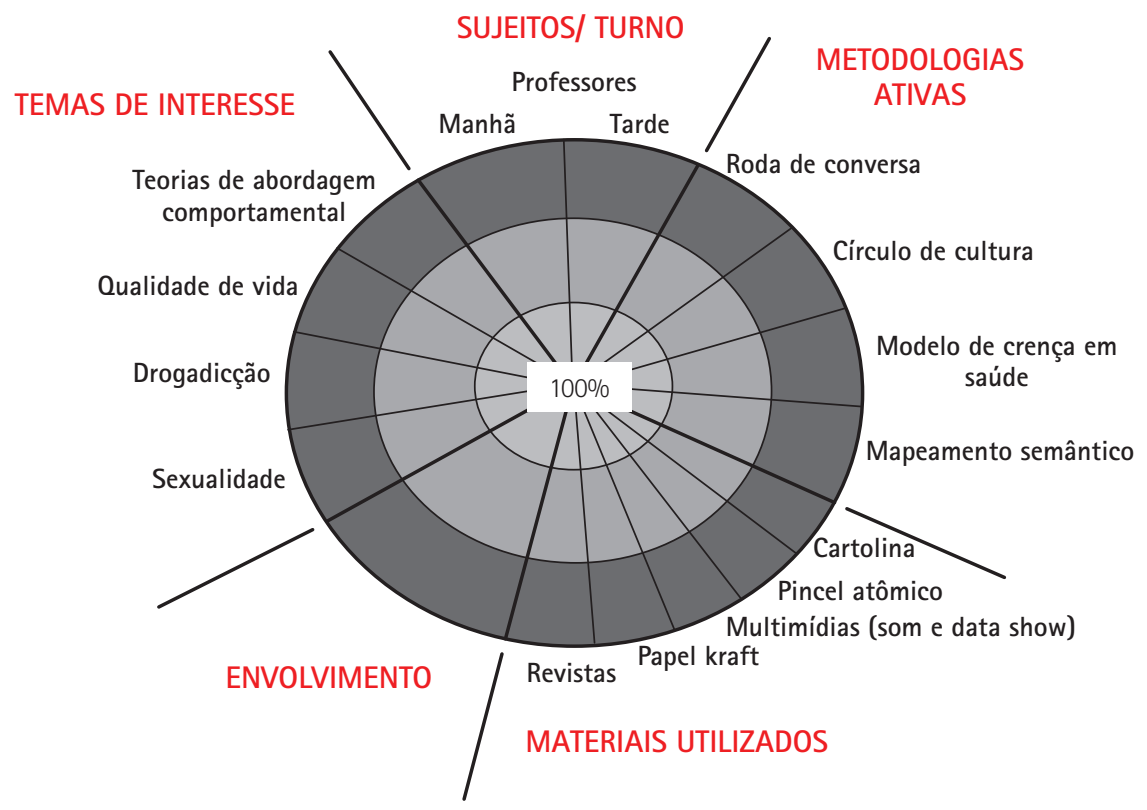

Fonte: Adaptada de Associação Brasileira de Educação Médica (2009).

As narrativas das crianças e dos adolescentes confirmaram que a utilização de dinâmicas que estimulam a participação ativa os motiva, pois assim eles conseguem internalizar o conhecimento com mais facilidade, compreendendo que a saúde é uma construção social pela qual todos são responsáveis.

As observações realizadas durante as rodas de conversas, concatenadas às narrativas dos participantes, levam-nos a inferir que a educação em saúde tem boa aceitabilidade pelos escolares, desde que sua abordagem seja com metodologias ativas e significativas. Outro fenômeno identificado foi a causa da não realização desse processo educativo por parte dos docentes, a qual se caracteriza pelo despreparo deles sobre como inseri-lo no contexto da sala de aula, com dinâmicas ativas que levem crianças e adolescentes a participar sem dispersão.

A família foi um dos temas geradores que, em consequência de sua polissemia conceitual e complexidade, gerou inúmeros debates entre os participantes, destacando que o comportamento dos escolares é um reflexo da dinâmica familiar vivida, a qual reverbera em hábitos não saudáveis e violentos das crianças e dos adolescentes, reflexos do adoecimento familiar, consequência de uma sociedade doente, cuja cura perpassa primeiro pela educação. 


\title{
CONCLUSÃO
}

Da execução do projeto de extensão com interface na pesquisa "Diálogo e práxis: inovando práticas pedagógicas em educação em saúde nas escolas" em voga, emergiu uma comunicação de discernimento, que foi permeada de significâncias (sentidos) e contribuiu para legitimar entre os professores e gestores das escolas municipais e acadêmicos da UFMT que a educação e a saúde são fenômenos e necessidades sociais complementares e interdependentes, razão pela qual a nossa preocupação se dá na insistência da educação e da saúde como binômio indissociável.

0 binômio em questão é efetivado no ambiente escolar com crianças e adolescentes desde que o processo educativo seja desenvolvido com metodologias ativas, nas quais o diálogo se dá por uma comunicação com linguagem lúdica e significativa, em que a escuta ativa e a fala são ferramentas propulsoras da ação.

A saúde está imbricada na educação e vice-versa, pois a existência de uma é interdependente da outra; portanto, uma não suplanta a outra, sendo a infância e adolescência as etapas do ciclo vital que são apropriadas para aprendizagens que poderão se perpetuar na vida adulta, contribuindo para a construção de uma sociedade mais saudável.

Concluímos que a criança e o adolescente, quando têm espaço de voz ativa e escuta no processo educativo, tornam-se sujeitos ativos e reflexivos, multiplicadores em seus lares e na comunidade quanto aos hábitos e comportamentos necessários para construção social da saúde, podem exercer sua cidadania no que concerne à busca da garantia dos seus direitos à educação e à saúde assegurados constitucionalmente.

Sugerimos que mais projetos dessa natureza sejam realizados e que haja capacitação de mais professores e gestores escolares sobre a arte de educar em saúde na ambiência escolar, para a concretização de termos famílias saudáveis e um mundo com cultura de paz, saúde mental e exercício da cidadania desde a infância.

\section{Communication of the inseparable binomy in school: education and health}

\begin{abstract}
This article aims to discuss the binomial education and health environment the school. Points out problems of the late 18th century raised by the German Johann Peter Frank (1745-1821), who published in 1779 in Germany, a guide entitled System Einer Vollstãndigen Medicinischen (1976), whose English version is: A system of complete medical police. School health is thought in programs turned to its implementation. Lescura and Mamede (1990) emphasize that health education in schools is an educational practice. In Brazil, health imbricated with education and vice versa, enabled the existence of problematizations about childhood and adolescence, the stages of the life cycle and health in the School Health Program - PSE in the school environment, for the
\end{abstract}


realization of healthy families and a world with a culture of peace, mental health and the exercise of citizenship since childhood. In order to boost the relations of public health actors in an educational integration process, the action and projects of the Family Health Teams were analyzed, the need for technical insertion in the Health at School Program - Group of Multiprofessional Researches in Education and Technologies in (PEMEDUTS) of the Faculty of Medicine of the Federal University of Mato Grosso (UFMT), Cuiabá campus - Extension Project Keywords: Education. Health. Communication. School environment. Project.

\section{REFERÊNCIAS}

ASSOCIAÇÃO BRASILEIRA DE EDUCAÇÃO MÉDICA. Comissão de avaliação das escolas médicas: objetivos, implementação e resultados preliminares 2006-2009. Rio de Janeiro: Abem, 2009.

BARBOSA, R. André Franco Montoro. O Globo, 8 ago. 2006. Disponivel em: https://www2.senado.leg.br/bdsf/bitstream/handle/id/401898/noticia.htm?sequence=1. Acesso em: 10 ago. 2020.

BRASIL. Decreto n. 6.286, de 5 de dezembro de 2007. Institui o Programa Saúde na Escola PSE e dá outras providências. Diário Oficial da República Federativa do Brasil, 2007. Disponivel em: http://www.planalto.gov.br/ccivil_03/_ato2007-2010/2007/decreto/d6286.htm\#: : text=DECRET0\%20N\%C2\%BA\%206.286\%2C\%20DE\%205,que\%20lhe\%20confere\%20 o\%20art. Acesso em: 2 jul. 2020.

BRASIL. Portaria n. 1.861, de 4 de setembro de 2008. Diário Oficial da República Federativa do Brasil, n. 185, 24 set. 2008. Disponivel em: http://bvsms.saude.gov.br/bvs/saudelegis/gm/ 2008/prt1861_04_09_2008.html. Acesso em: 2 jul. 2020.

BRASIL. Portaria Interministerial n. 3.682, de 25 de novembro de 2010. Diário Oficial da República Federativa do Brasil, n. 226, 26 nov. 2010. Disponivel em: http://bvsms.saude.gov.br/ bvs/saudelegis/gm/2010/pri3682_25_11_2010.html. Acesso em: 2 jul. 2020

BRASIL. Portaria Interministerial n. 1.413, de 10 de julho de 2013. Diário Oficial da República Federativa do Brasil, 2013. Disponivel em: http://bvsms.saude.gov.br/bvs/saudelegis/gm/2013/ pri1413_10_07_2013.html. Acesso em: 2 jul. 2020.

CUIABÁ. Decreto n. 4.684, de 20 de junho de 2008. Dispõe sobre a implantação do programa escola com saúde e dá outras providências. Legislação Municipal de Cuiabá, 20 jun. 2008. Disponivel em: http://Imc.cuiaba.mt.gov.br/mostrar-documento-publico?codigo=2491. Acesso em: 10 jul. 20.

DELEUZE, G.; GUATTARI, F. Mil platôs. Tradução Ana Lúcia de Oliveira, Aurélio Guerra Neto e Célia Pinto Costa. São Paulo: Editora 34, 2011. v. 1. 
DELORS, J. Educação: um tesouro a descobrir. São Paulo: Cortez, 1999.

FIGUEIREDO, T. A. M.; MACHADO, V. L. T.; ABREU, M. M. S. A saúde na escola: um breve resgate histórico. Ciências \&t Saúde Coletiva, v. 15, n. 2, p. 397-402, 2010. Disponivel em: https:// www.scielo.br/scielo.php?script=sci_arttext\&tpid=S1413-81232010000200015. Acesso em: 2 jul. 2020.

FRANK, J. P. A system of complete medical police. Baltimore: The Johns Hopkins Press, 1976.

FREIRE, P. Educação como prática da liberdade. Rio de Janeiro: Paz e Terra, 1967.

FREIRE, P. Pedagogia do oprimido. São Paulo: Paz e Terra, 1974.

FREIRE, P. Pedagogia da autonomia: saberes necessários à prática educativa. 36. ed. São Paulo: Paz e Terra, 1996.

LESCURA, Y.; MAMEDE, M. V. Educação em saúde: abordagem para o enfermeiro. São Paulo: Sarvier, 1990.

MARTINHO, N. J. Projeto de extensão: Diálogo e práxis: inovando práticas pedagógicas em educação em saúde nas escolas. Universidade Federal de Mato Grosso, 2018. Disponível em: https://sistemas.ufmt.br/ufmt.siex/Projeto/Detalhes?projetoUID=46. Acesso em: 2 jul. 2020.

MELO, J. A. C. Educação sanitária: uma visão crítica. Cadernos do CEDES, v. 4, p. 28-43, 1987. PRUDENTE, C. L. A dimensão pedagógica do cinema negro. In: AVANCA CINEMA. Conferência Internacional de Cinema, Arte, Tecnologia e Comunicação. Avanca: Cineclube Avanca, 2018. v. 1, p. 307-313.

PRUDENTE, C. L. Étnico léxico: para compreensão do autor. In: SILVA, D. C. (org.). A dimensão pedagógica do cinema negro: aspectos de uma arte para a afirmação ontológica do negro brasileiro: o olhar de Celso Prudente. 2. ed. São Paulo: Anita Garibaldi, 2019a. p. 171-177.

PRUDENTE, C. L. A dimensão pedagógica do cinema negro: a imagem de afirmação positiva do ibero-ásio-afro-ameríndio. Extraprensa, São Paulo, v. 13, n. 1, p. 6-25, 20196.

PRUDENTE, C. L. A fragmentação do mito da democracia racial e a dimensão pedagógica do cinema negro. Revista Internacional em Língua Portuguesa, n. 38, p. 157-171, 6 ago. 2020. DOI: 10.31492/2184-2043.RILP2020.38/pp.157-171.

RIBEIRO, C. M. Imaginário das águas andaluzas para surfar pela invisibilidade dos negros e negras de Sevilha. In: PRUDENTE, C. L. (org.). $15^{\circ}$ Mostra Internacional do Cinema Negro. São Paulo: Sesc, 2019. p. 56-63.

SILVA, C. P. et al. Educação em saúde: uma revisão histórico-crítica com enfoque no municipio de Sobral-CE. Sanare - Revista de Políticas Públicas, Sobral, v. 9, n. 2, p. 29-37, 2010. 
Disponivel em: file://C:/Users/Celso\%20Luiz\%20Prudente/Downloads/4-3-1-SM\%20(1).pdf. Acesso em: 15 ago. 2020.

VELASCO, R. Programa Saúde na Escola recebe adesão de 139 municipios em Mato Grosso. SES/MT, 22 mar. 2019. Disponivel em: http://www.mt.gov.br/rss/-/asset_publisher/Hf4xlehMolwr/content/id/11470838. Acesso em: 2 jul. 2020.

Recebido em agosto de 2020. Aprovado em novembro de 2020. 